\title{
Finite Element Analysis's Interrelationship Equation to Predict the Deflection of Rolled Homogeneous Armor Steel Plate Due to Explosion based on Different Explosive Masses and Plate Thicknesses
}

\author{
Md Fuad Shah Koslan ${ }^{1,2}$, Mohd Zaid Othman ${ }^{2}$ \& Ahmad Mujahid Ahmad Zaidi ${ }^{2,3}$ \\ ${ }^{1}$ Royal Malaysian Air Force, Ministry of Defence, Kuala Lumpur, Malaysia \\ ${ }^{2}$ Department of Mechanical Engineering, Faculty of Engineering, National Defence University of Malaysia, \\ Sungai Besi Camp, 57000 Kuala Lumpur, Malaysia \\ ${ }^{3}$ International College of Automotive (ICAM), Pekan, Pahang, Malaysia \\ Correspondence: Mohd Zaid Othman, Department of Mechanical Engineering, Faculty of Engineering, National \\ Defence University of Malaysia, Kuala Lumpur, Malaysia. Tel: 60-124-045-002. E-mail: zaid002@gmail.com
}

Received: November 4, 2014

Accepted: November 14, $2014 \quad$ Online Published: January 19, 2015

doi:10.5539/mas.v9n4p178

URL: http://dx.doi.org/10.5539/mas.v9n4p178

\begin{abstract}
This paper presents the interrelationship equation to predict the deformations of square rolled homogeneous armor steel plate subjected to spherical shape trinitrotoluene charge by using finite element analysis software i.e. AUTODYN 3D. The investigation starts by producing computer simulation process using AUTODYN 3D so that a set of experimental tests deformations' data of rolled homogeneous armor steel plate from a published work can be used to validate the computer simulations outputs and good agreements are observed. Parametric studies are then performed on the design parameters of the explosive and the rolled homogeneous armor steel plate, where the mass of the explosive and the thickness of the rolled homogeneous amour steel plate are varied and analyzed by using the AUTODYN 3D computer simulations. Curve fitting method is then performed to produce the interrelationship equation that could be utilized by researchers as an initial prediction method in determining the deformation of rolled homogeneous armor steel plate subjected to explosive charge and the interrelation equation is valid and can be utilized for a standoff distance of $200 \mathrm{~mm}$, plate's thickness of $15 \mathrm{~mm}$ to $30 \mathrm{~mm}$ and explosive mass of $1.5 \mathrm{~kg}$ to $10 \mathrm{~kg}$.
\end{abstract}

Keywords: solver coupling, computational simulation, AUTODYN 3D, interrelationship equation, RHA plate

\section{Introduction}

Design of armor solutions that provide adequate protection without sacrificing the functionality or adding too much mass are considered as a serious challenge. Each experimental test of an armored vehicle's resistance towards blast loading typically destroys the armor and or the vehicle, while making repeated experimental tests are both expensive and time consuming. Thus, precise prediction of explosions and the associated response of the armored vehicle considered an important part through the design process for armored vehicles (G Schleyer, 2010). Hence, with the excess of reliable and accurate computer simulations as well as mathematical-based design optimization, can be utilized in designing stronger, more efficient and lower cost armor for armored vehicles.

Various techniques have been developed as a means of protection against the destructive effect of blast waves. As an example, researchers (Chung Kim Yuen et al., 2005) studied the response of quadrangular stiffened mild steel plate subjected to blast loading through experimental and numerical methods and the study was continued by another group of researchers (Langdon et al., 2010), where the authors studied the performance of mild steel perforated plates toward blast loading. An investigation on metallic sandwich panel deformation and failure behavior subjected to blast loading by changing the face-sheet, core and charge mass configuration has also been performed (Feng Zhu et al., 2008). The response of curvature plate when imposed on blast loading was presented by Kumar et al. (Kumar et al, 2012). However, the study performed by Feng Zhu et al. (Feng Zhu et al., 2008) only utilized aluminum material. Thus, there plenty of studies that could still be carried out by varying the material and configuring the parameters. 
Experimental tests as performed by Neuberger et al. (Neuberger et al., 2009) were used to validate the computer simulation models in this study and various parameters were considered in the computer simulation analyses. In this study, AUTODYN 3D computer simulation code identifies the effects of rolled homogeneous armor (RHA) plate thickness as an undercarriage shield when subjected to various TNT weights as blast loading, thus a new interrelationship equations were obtained based on AUTODYN 3D computer simulations to facilitate the preliminary aspects of military vehicle designs subjected to blast loads.

\section{Method}

\subsection{Validation Analysis}

The experimental test performed by Neuberger and his co-researchers (Neuberger et al., 2009) was taken as a reference to validate the AUTODYN 3D computer simulation outputs, the three cases are as shown in Table 1.

Table 1. Three experimental blast tests performed by Neuberger and his co-researchers (Neuberger et al., 2009)

\begin{tabular}{|c|c|c|c|}
\hline Test case & $\begin{array}{ll}\text { Plate thickness }(\mathrm{mm}) \\
\end{array}$ & Standoff distance $(\mathrm{mm})$ & Size of TNT $(\mathrm{kg})$ \\
\hline $\mathrm{a}$ & 20 & 200 & 3.75 \\
\hline $\mathrm{b}$ & 20 & 200 & 8.75 \\
\hline $\mathrm{c}$ & 20 & 130 & 8.75 \\
\hline
\end{tabular}

The computer simulation model was created in a domain size of $(530 \times 500 \times 530) \mathrm{mm}$ with $5 \mathrm{~mm} \times 5 \mathrm{~mm} \times 5$ $\mathrm{mm}$ of element size defined as air and was symmetrical in the ' $\mathrm{x}$ ' and ' $\mathrm{z}$ ' planes. Based on the analysis performed by Koslan et al. (Koslan et al., 2013) it was found the best element size for AUTODYN 2D was about $0.65 \mathrm{~mm}$. However, the computer simulation will take longer time if the same size of element in 2D used for the three-dimensional (3D) model. Thus, for the 3D analysis, $1 \mathrm{~mm} \times 1 \mathrm{~mm} \times 1 \mathrm{~mm}$ size of element was selected. The RHA plate panel modeled with quadrilateral element with a $1 \mathrm{~mm}$ edge length. A quarter of symmetry model was used in the simulation in order to reduce the computational time. It was modeled in AUTODYN 3D as shown in Figure 1, giving 24 different cases and were summarized as shown in Table 3.

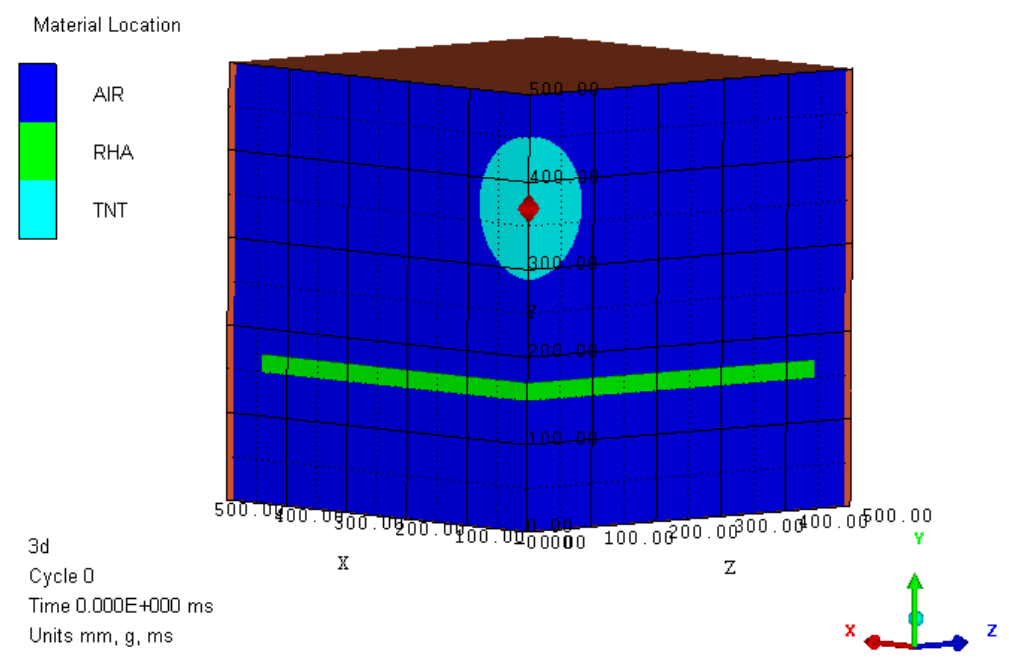

Figure 1. A three-dimensional simulation model created in AUTODYN 3D

\subsection{Boundary Condition}

The RHA material properties used in the simulation model were obtained from (Neuberger et al., 2007) as shown in Table 2. It was found that Arbitrary Lagrange Euler (ALE) was the most suitable solver used to calculate the interaction between the TNT explosive and the RHA plate because ALE consists of Langrage and Euler algorithms. For fluid-structure interaction phenomenon, element distortions usually occur when there exist interactions between solid and fluid, in blast related scenario; solid element will be transformed into fluid 
element after an explosion occurs, at this particular moment, the Lagrange algorithm has to be analyzed as an Euler algorithm. With respect to the equation of state (EOS), Johnson and Cook for the material and Jones Wilkins Lee (JWL) for the TNT, and the Euler solver was used to represent air with respect to the ideal gas EOS. The displacement gauge was located at the center of the plate at a coordinate of $(0,160,0)$.

Table 2. Material properties for RHA (Neuberger et al., 2007)

\begin{tabular}{cccccccccccc}
\hline$t$ & $\sigma_{Y}$ & $\sigma_{U T S}$ & $\varepsilon$ & $E$ & $v$ & Hardness & $A$ & $B$ & $n$ & $c$ & $m$ \\
$(m m)$ & $(M P a)$ & $(M P a)$ & $(\%)$ & $(G P a)$ & & $(H B W)$ & $(M P a)$ & $(M P a)$ & & & \\
\hline $3-20$ & 950 & 1250 & 9 & 210 & 0.28 & $380-430$ & 950 & 560 & 0.26 & 0.0014 & 1 \\
\hline
\end{tabular}

where, $\mathrm{t}$ is known as thickness, $\sigma_{Y}$ is the yield stress, $\sigma_{U T S}$ is the ultimate tensile stress, $\varepsilon$ is the strain, $E$ is the Young's Modulus, $v$ is the Poisson's ratio. The constants; $A, B, n, C$ and $m$ are normally user-defined constants and obtained from an empirical of flow stress data.

\subsection{Parametric Analysis}

This study investigates the effect of armor plates with different selected thickness subjected to the various amount of blasts loading. Adisak (Adisak Showichen, 2008) has classified five modes of attack; track attack, belly attacks, full-width attack, side attack and top attack. It was found that most of the armored vehicle was attacked at the bottom side or full-width attack. However, most of the geometry information of bottom structure armored vehicle remains classified and restricted to the public access. Therefore, for studying purposes only, the armored vehicle ground clearance was represented by a fixed standing off distance parameter of $200 \mathrm{~mm}$ and the hull dimension was represented by the size of plate.

According to Foss (Foss, 2000), average military vehicle has a ground clearance between 200-600 mm. Furthermore, Foss also indicated that most of the armored vehicle's hull dimensions at $2.0 \mathrm{~m}$ to $4.0 \mathrm{~m}$ wide x $4 \mathrm{~m}$ to $8 \mathrm{~m}$ long x $1.7 \mathrm{~m}$ high. Based on full armored vehicle geometry, the derivation of the $1 / 4$ model used in the simulation analysis as illustrated in Figure 2.

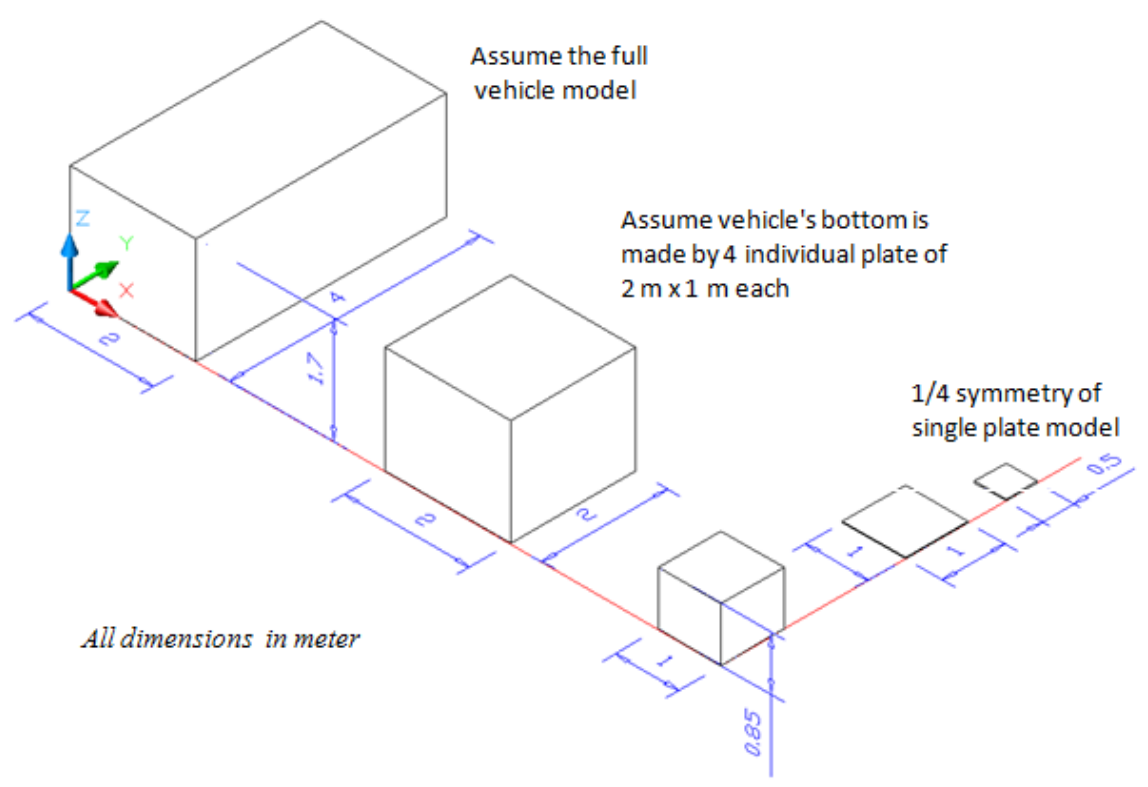

Figure 2. Schematic drawing on the derivation of $1 / 4$ model base on full armoured vehicle diagram

The blast loads acting on the RHA plate was based on the data from the work done by (Adisak Showichen, 2008), from all 168 types of mine it was found out that the mean charge weight was $6.13 \mathrm{~kg}$ TNT. Considering the blast mine only, it was found out that the average charge weight was $6.13 \mathrm{~kg}$ TNT while $3.75 \mathrm{~kg}$ TNT for shape charge 
and $7 \%$ of all has charge weight more than $10 \mathrm{~kg}$ TNT.

Numerical simulations were carried out using the AUTODYN 3D finite element (FE) code. The assumption made in the simulation was symmetrical, such that a quarter $(1 / 4)$ rectangular plate constructed to reduce the computational time associated with a full three dimensional model, as shown in Figure 2. It could be further simplified by assuming an axisymmetric modeling space; however, a half-model of three dimensional model would capture some realistic physical characteristics of the blast loading not considered in an axisymmetric model, without compromising the computational resources.

Thus, this paper presents the deformation of RHA plate subjected to $1.5 \mathrm{~kg}, 3.75 \mathrm{~kg}, 5 \mathrm{~kg}, 6.13 \mathrm{~kg}, 8.75 \mathrm{~kg}$ and $10 \mathrm{~kg}$ of TNT. A fixed stand-off distance of $200 \mathrm{~mm}$ has been taken in order to see a more pronounced effect of deformation and various thicknesses of $15,20,25$ and $30 \mathrm{~mm}$ been taken as the study parameters. The parameters for the case study are as shown in Table 3.

Table 3. The numerical calculations cases

\begin{tabular}{ll}
\hline $\mathrm{W}(\mathrm{kg}$ TNT $)$ & $10,8.75,6.13,5,3.75,1.5$ \\
\hline Area $\left(\mathrm{m}^{2}\right)$ & 0.25 \\
$\mathrm{R}(\mathrm{m})$ & 0.2 \\
$\mathrm{t}(\mathrm{mm})$ & $15,20,25,30$ \\
\hline
\end{tabular}

\section{Results}

\subsection{Validation}

The validation result of the RHA plate response subjected to the blast loading had been performed with the AUTODYN 3D software as shown in Figure 3. By performing the computer simulation method it was found that the residual deflection had a small difference between various methods as shown in Figure 3. This preliminary phase showed a good agreement between the experimentally measured deflections, and those calculated by using computer simulation model. This verification phase confers the reliability to the numerical model, and in conclusion the rest of the study done based on the FE simulation. This paper examines the relationship between deformations of the plate with the various plate thicknesses when the explosion blast load applied using AUTODYN 3D computer code.

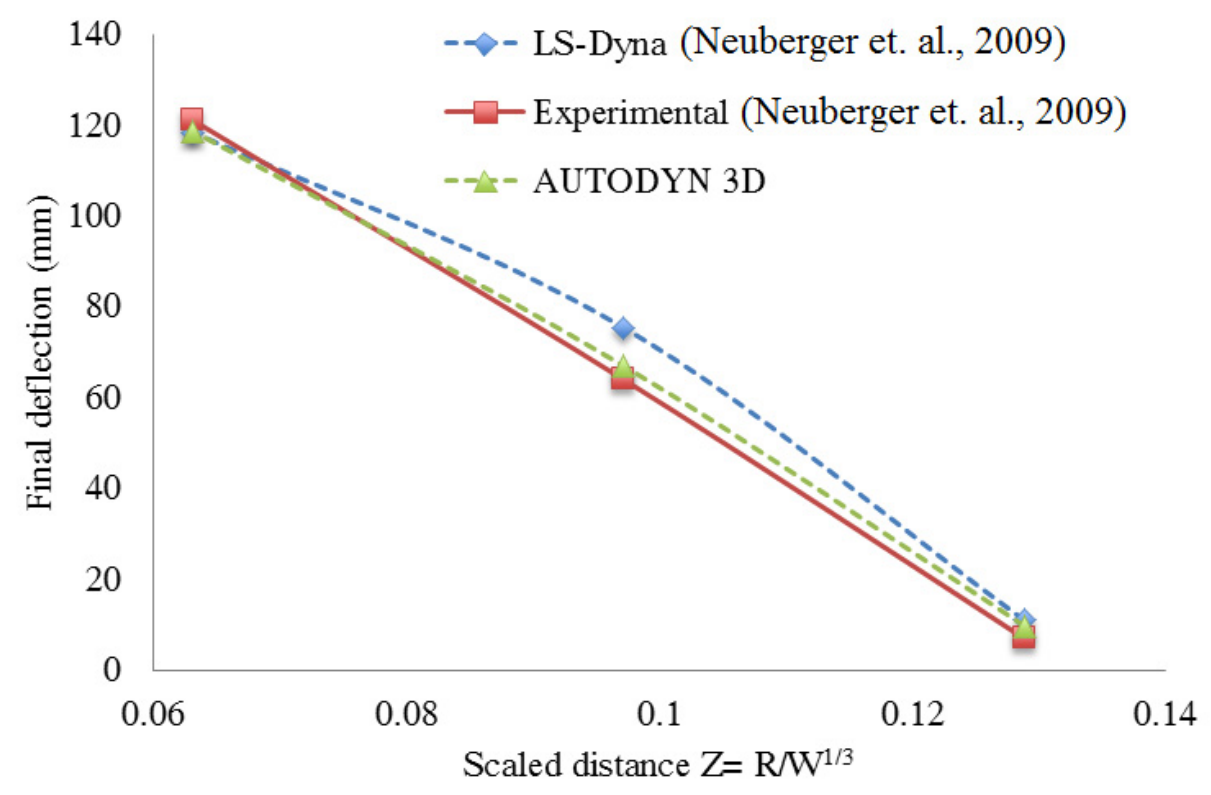

Figure 3. Comparison on residual deflection from various methodologies 


\subsection{Parametric Analysis}

The computational models were built to predict the deformation of several thickness of RHA plate towards various amounts of blast charge. The obtained numerical results were tabulated as shown in Table 4 and lead towards the interrelationship equation as well as the involved relation parameters were discussed.

Table 4. AUTODYN 3D simulation result by varying the thickness of the RHA plate and masses of TNT

\begin{tabular}{|c|c|c|c|c|c|c|}
\hline Model number & $\begin{array}{l}\text { Thickness, } \\
t(\mathrm{~mm})\end{array}$ & $\begin{array}{l}\text { TNT charge, } \\
m(\mathrm{~kg})\end{array}$ & $\begin{array}{l}\text { Maximum } \\
\text { deflection, } \\
\delta_{\max }(\mathrm{mm})\end{array}$ & $\begin{array}{l}\text { Residual } \\
\text { deflection, } \\
\delta_{\text {res }}(\mathrm{mm})\end{array}$ & $\begin{array}{l}\text { Maximum } \\
\text { deflection-plate } \\
\text { thickness ratio } \\
(\delta / t)_{\max }\end{array}$ & $\begin{array}{l}\text { Residual } \\
\text { deflection-plate } \\
\text { thickness ratio } \\
(\delta / t)_{\text {res }}\end{array}$ \\
\hline $\mathrm{s} 200 \mathrm{t} 15 \mathrm{e} 10$ & 15 & 10 & 102.41 & 100.04 & 6.83 & 6.67 \\
\hline s200t15e8.75 & & 8.75 & 95.67 & 92.21 & 6.38 & 6.15 \\
\hline s200t15e6.13 & & 6.13 & 78.55 & 59.13 & 5.24 & 3.94 \\
\hline s200t15e 5 & & 5 & 59.9 & 21.5 & 3.99 & 1.43 \\
\hline s200t15e3.75 & & 3.75 & 49.3 & 16 & 3.29 & 1.07 \\
\hline $\mathrm{s} 200 \mathrm{t} 15 \mathrm{e} 1$ & & 1 & 28.53 & 1.86 & 1.9 & 0.12 \\
\hline s200t20e10 & 20 & 10 & 85.76 & 75.13 & 4.24 & 3.76 \\
\hline s200t20e8.75 & & 8.75 & 77.41 & 66.95 & 3.87 & 3.35 \\
\hline s200t20e6.13 & & 6.13 & 63.81 & 41.7 & 3.19 & 2.09 \\
\hline $\mathrm{s} 200 \mathrm{t} 20 \mathrm{e} 5$ & & 5 & 50.98 & 13.74 & 2.55 & 0.69 \\
\hline $\mathrm{s} 200 \mathrm{t} 20 \mathrm{e} 3.75$ & & 3.75 & 39.78 & 2.37 & 1.99 & 0.12 \\
\hline $\mathrm{s} 200 \mathrm{t} 20 \mathrm{e} 1$ & & 1 & 21.56 & 0.1 & 1.08 & 0.005 \\
\hline $\mathrm{s} 200 \mathrm{t} 25 \mathrm{e} 10$ & 25 & 10 & 71.18 & 50.73 & 2.84 & 2.03 \\
\hline $\mathrm{s} 200 \mathrm{t} 25 \mathrm{e} 8.75$ & & 8.75 & 66.6 & 49.94 & 2.66 & 1.99 \\
\hline $\mathrm{s} 200 \mathrm{t} 25 \mathrm{e} 6.13$ & & 6.13 & 53 & 30.2 & 2.12 & 1.21 \\
\hline $\mathrm{s} 200 \mathrm{t} 25 \mathrm{e} 5$ & & 5 & 43.82 & 5.42 & 1.75 & 0.22 \\
\hline $\mathrm{s} 200 \mathrm{t} 25 \mathrm{e} 3.75$ & & 3.75 & 32.02 & 2.13 & 1.28 & 0.09 \\
\hline $\mathrm{s} 200 \mathrm{t} 25 \mathrm{e} 1$ & & 1 & 15.74 & 0.04 & 0.63 & 0.0017 \\
\hline s200t30e10 & 30 & 10 & 60 & 41 & 2 & 1.37 \\
\hline $\mathrm{s} 200 \mathrm{t} 30 \mathrm{e} 8.75$ & & 8.75 & 55 & 37.74 & 1.83 & 1.26 \\
\hline s200t30e 6.13 & & 6.13 & 42.7 & 20.4 & 1.42 & 0.68 \\
\hline $\mathrm{s} 200 \mathrm{t} 30 \mathrm{e} 5$ & & 5 & 34.8 & 4.67 & 1.16 & 0.16 \\
\hline $\mathrm{s} 200 \mathrm{t} 30 \mathrm{e} 3.75$ & & 3.75 & 26.15 & 2.03 & 0.87 & 0.07 \\
\hline $\mathrm{s} 200 \mathrm{t} 30 \mathrm{e} 1$ & & 1 & 11.68 & 0.02 & 0.39 & 0.0007 \\
\hline
\end{tabular}

\section{Discussion}

It is important to consider the mechanics of the impact phenomena and thus deduce the relevant non-dimensional numbers. The numerical value of a variable such as deflection $(\delta)$ depended on the values of all quantities that distinguish while impact loading. The involved independent variable has determined as following; stand-off distance $(R)$, the mass of TNT $(m)$, thickness of plate $(t)$. The plate material properties also played a role. The theoretical understanding of solid mechanics tells us that, the inertial effects, which inevitably come into play during collision and reflect, also depend on the material's density $(\rho)$. Therefore, the plate deflection generally defined as.

$$
\delta=f(t, R, m, \rho)
$$

From Buckingham's p theorem (Sonin, 2001 and Qadir Bux alias Imran Latif et al., 2011), there existed 3 non-dimensional groups. It can be express as shown below:

$$
\begin{gathered}
\phi(\delta, R, m, \rho)=0 \\
\phi\left(\pi_{1}, \pi_{2}, \pi_{3}\right)=0
\end{gathered}
$$

In the system unit, the dimensions of the quantities in Equation (1) as follows:

Independent quantities: $[t]=L,[R]=L,[m]=M$, and $[\rho]=M L^{-3}$

Dependent quantities: $[\delta]=L$ 
non-dimensionlized the remaining independent variables $\rho$ and the dependent variable $\delta$ by dividing them by $t, R$ respectively, as suggested by Equation (2):

$$
\pi_{1}=\frac{\rho t^{3}}{m}, \pi_{2}=\frac{\delta}{t}, \pi_{3}=\frac{\delta}{R}
$$

Hence the physical situation described by this function of non-dimensional numbers as follows:

$$
\varnothing\left(\pi_{1}, \pi_{2}, \pi_{3}\right)=\phi\left(\frac{\rho t^{3}}{m}, \frac{\delta}{t}, \frac{R}{t}\right)
$$

A non-dimensional analysis plate deflection subjected to blast loading based on Equation (4) leads to:

$$
\frac{\delta}{t}=\phi\left(\frac{R}{t}, \frac{\rho t^{3}}{m}\right)
$$

Since the stand-off distance value in this study been fixed at $200 \mathrm{~mm}$ then the interrelationship equation established as follows:

$$
\frac{\delta}{t}=\phi\left(\frac{\rho t^{3}}{m}\right)
$$

Due to the complexity in this field, obtaining interrelationship equation based on computer simulation approach considered very important. This correlation, i.e. for plate deflection often formulated by curve fitting test data, and thus, the validity only applicable in its operating range. The interrelationship equation developed from the residual and maximum deflection of the plate towards plate thickness $\delta / t$ by using a power function as:

$$
y=a x^{n}
$$

Based on Equation (5) the general equation for plate deflection subjected to blast loading as following:

$$
\frac{\delta}{t}=a\left(\frac{\rho t^{3}}{m}\right)^{n}
$$

$a$ and $n$ values were to be determined by the data collection.

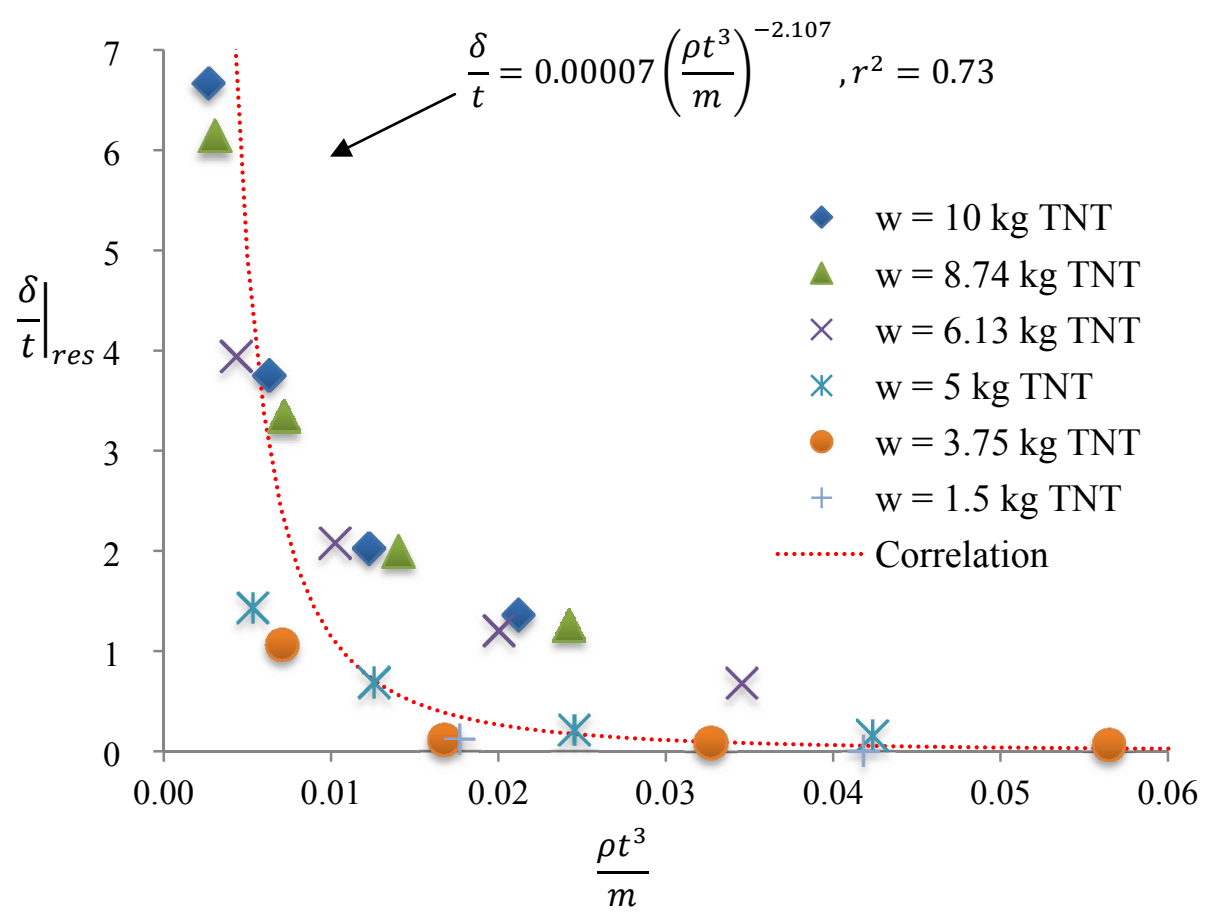

Figure 4. The results of a newly developed interrelationship equation and comparison with residual deflection prediction of FEM simulation 
The predicted results were consistently lower than the numerical results as shown in Figure 4 and Figure 5, although overall predictions provides relatively average results as compared to the simulation work. The $\mathrm{r}^{2}$-value shows the proposed interrelationship equation obtained were relatively average out to a prediction of 70 and 98 percent accurate for final and maximum deflection respectively as compared to the numerical simulation. The interrelationship equation only applicable in it's valid operating range. The proposed formula also can be used for the RHA flat plate within the range of $15 \mathrm{~mm}$ to $30 \mathrm{~mm}$ thicknesses when subjected to blast loading range of $1.5 \mathrm{~kg}$ to $10 \mathrm{~kg}$ of TNT at the stand-off distance of $200 \mathrm{~mm}$.

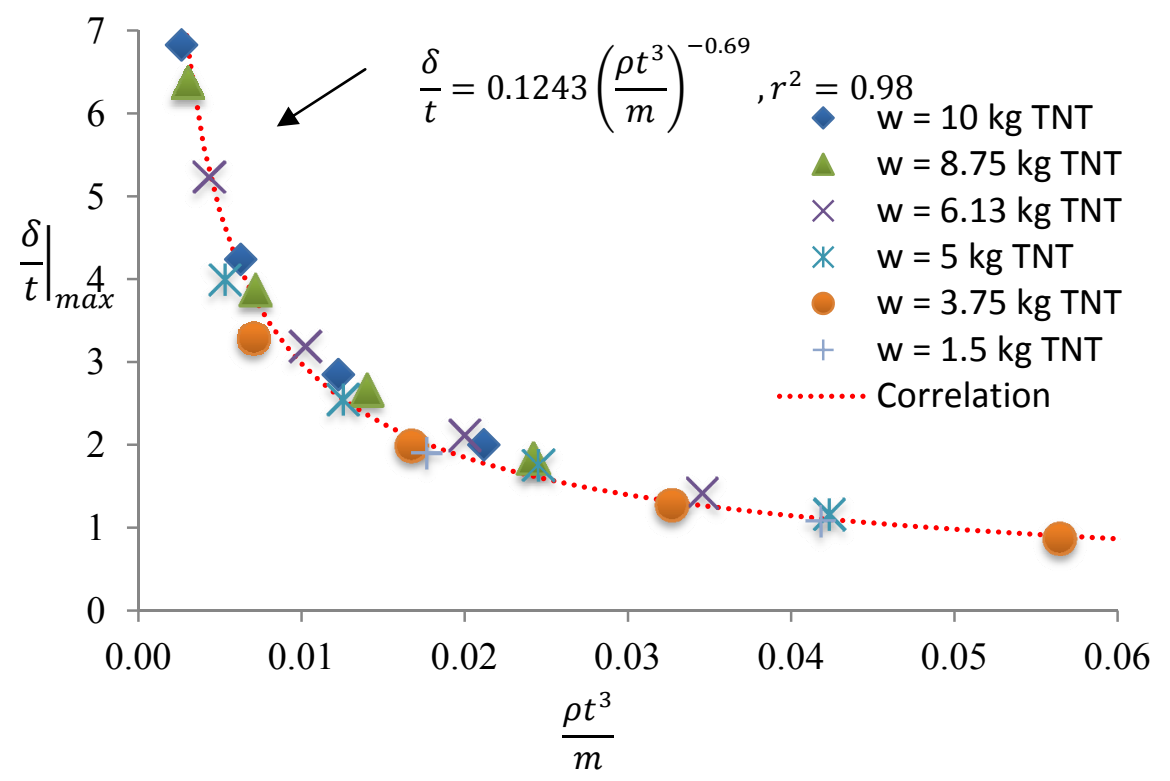

Figure 5. The results of a newly developed interrelationship equation and comparison with maximum deflection prediction of FEM simulation

Based on Figures 4 and 5, Equation (8) for plate residual and maximum deflections are obtained as follows:

$$
\begin{aligned}
& \left.\frac{\delta}{t}\right|_{\text {residual }}=0.00007\left(\frac{\rho t^{3}}{m}\right)^{-2.107} \\
& \left.\frac{\delta}{t}\right|_{\text {maximum }}=0.1243\left(\frac{\rho t^{3}}{m}\right)^{-0.69}
\end{aligned}
$$

The interrelationship equation obtained based on numerical simulation data facilitates the preliminary study for a design, and it has been successfully discovered in this paper and since the resulting interrelationship equation was obtained based on 24 case of computer simulations, predictions could be further improved if the data from all 24 cases were acquired through physical experimental field tests. However, the results obtained from the proposed developed interrelationship equation shows relatively average predictions, as compared to numerical simulation, and sometimes under predict and over predict results. Further work i.e. using different stand-off distance subjected to various amounts of charge mass can be undertaken to extend the current investigation.

\section{Acknowledgements}

Financial assistance from the Royal Malaysian Air Force (RMAF) towards this research is hereby acknowledged. Opinions and views either directly or indirectly from various parties, including staffs and lecturers from Centre for Advanced Armored Vehicle are greatly appreciated.

\section{References}

Adisak, S. (2008). Numerical Analysis of Vehicle Bottom Structure Subjected to Anti-Tank Mine Explosions. Ph.D. Thesis, Cranfeild University, United Kingdom.

Ain, A. S. (2001). The Physical Basis of Dimensional Analysis. Department of Mechanical Engineering, MIT Cambridge.

Chung, S., Kim, Y., \& Nurick, G. N. (2005). Experimental and Numerical Studies on The Respons of 
Quadrangular Stiffened Plates. Part I: Subjected to Uniform Blast Load. International Journal of Impact Engineering, 31, 55-83. http://dx.doi.org/10.1016/j.ijimpeng.2003.09.048

Foss, C. F. (2000). Jane's Armor and Altellery. Great Britain: Jane's Information Group Limited.

Graham, S. (2010). Blast Response and SDOF Method. Impact and Blast Resistant Design Method. Wessex Institute of Technology, Ashurst Lodge, Ashurst, Southampton.

Langdon, G. S., Rossiter, I. B., Balden, V. H., \& Nurick, G. N. (2010). Performance of Mild Steel Perforated Plates as a Blast Wave Mitigation Technique: Experimental and Numerical Investigation. International Journal of Impact Engineering, 37, 1021-1036. http://dx.doi.org/10.1016/j.jimpeng.2010.06.001

Md Fuad Shah Koslan, Ahmad, M. A. Z., Mohd, Z. O., Shohaimi, A., \& Suresh, T. (2013). The Effect of Mesh Sizing Towards Deformation Result in Computational Dynamic Simulation for Blast Loading Application. Modern Applied Science, 7(7), Canadian Center of Science and Education. http://dx.doi.org/10.5539/mas.v7n7p23

Neuberger, A., Peles, S., \& Rittel, D. (2007). Scaling the Response of Circular Plates Subjected to Large and Close-Range Spherical Explosion. Part I: Air-Blast Loading. International Journal of Impact Engineering, 34, 859-873. http://dx.doi.org/10.1016/j.ijimpeng.2006.04.001

Neuberger, A., Peles, S., \& Rittel, D. (2009). Springback of Circular Clamped Armor Steel Plates Subjected to Spherical Air-Blast Loading. International Journal of Impact Engineering, 36, 53-60. http://dx.doi.org/10.1016/j.ijimpeng.2008.04.008

Puneet, K., James, L., David, S. S., \& Arun, S. (2012). Effect of Plate Curvature on Blast Response of Aluminum Panels. International Journal of Impact Engineering, 46, 74-85, http://dx.doi.org/10.1016/j.ijimpeng.2012.02.004

Qadir Bux alias Imran Latif, Ismail, A. R., \& Ahmad, M. A. Z. (2011). Development of Empirical formula Prediction on Critical Impact Energy for Perforation Phenomena on Concrete Structure. Journal of Mathematics Research, 3, 83-87. http://dx.doi.org/10.5539/jmr.v3n1p83

Zhu, F., Zhao, L. M., Lu, G. X., \&Wang, Z. H. (2008). Deformation and Failure of Blast-Loaded Metallic Sandwich Panel: Experimental Investigation. International Journal of Impact Engineering, 35, 937-951. http://dx.doi.org/10.1016/j.ijimpeng.2007.11.003

\section{Copyrights}

Copyright for this article is retained by the author(s), with first publication rights granted to the journal.

This is an open-access article distributed under the terms and conditions of the Creative Commons Attribution license (http://creativecommons.org/licenses/by/3.0/). 